\title{
Percent Unit
}

National Cancer Institute

\section{Source}

National Cancer Institute. Percent Unit. NCI Thesaurus. Code C48570.

A unit for expressing a number as a fraction of hundred (on the basis of a rate or proportion per hundred). 